\title{
Immunity of power line communications (PLC) in disturbed networks
}

\author{
B. Vallbè, J. Balcells, P. Bogónez-Franco, J. Mata, X. Gago \\ Universitat Politècnica de Catalunya. \\ bernat.va@gmail.com, josep.balcells@upc.edu, paco.bogonez@upc.edu, jmata@entel.upc.edu, xgago@eel.upc.edu
}

\begin{abstract}
This paper presents an analysis of electromagnetic immunity of energy metering devices, using broadband power line communications (PLC) in low voltage (LV) supply networks with high levels of disturbance. Several tests have been carried out to characterize the behavior of PLC modems and couplers in presence of the most common types of disturbances and electromagnetic interferences (EMI) which can be expected in LV distribution networks.

The method exposed allows repeat the tests with different modems, communications wires and couplers. Thus it is possible to compare different elements between them and choose the best for every occasion.
\end{abstract}

Keywords - Power line communications, PLC. Electromagnetic Interferences, EMI.

\section{INTRODUCTION}

There is an increasing interest on the implementation of remote energy metering, power quality monitoring, power demand management and supply network safety. The basis to implement all the mentioned functions in the electrical supply systems is the possibility of networking different electronic devices performing such functions and link them to a central computer [1] [2] [3]. Therefore, there is a growing interest on reliable and cheaper communications methods. Power Line Communications (PLC) through the supply networks themselves, seems to be the preferred solution to implement such communications systems, because of its availability and the relative low cost of the solution. Nowadays, the existing low voltage (LV) or medium voltage (MV) networks [4] [5] [6].

PLC communications systems operate by impressing a modulated carrier signal on the supply wiring system by means of a modem and a coupling interface. There are different types modems, using different frequency bands, depending on the signal transmission characteristics. Since the power wiring system was originally intended for transmission of AC power, the power wire circuits have only a limited ability to carry high frequencies and therefore, the propagation problem becomes a limiting factor for each type of power line communications. Data rates over a power line communication system vary widely from low-frequency carriers (about 100-200 $\mathrm{kHz}$ ) which can be impressed on high and medium voltage (HV, MV) lines allowing equivalent data rates of a few hundred bits per second. However, these circuits may be many kilometers long. Higher data rates generally imply shorter transmission lengths. For example, local area networks may operate at several $\mathrm{MHz}$. Depending on the frequency band and the type of modulation used, it's possible to obtain different speeds. For example, using $50 \mathrm{kHz}$ bandwidth the data rate may reach up to $130 \mathrm{kbps}$, while using $30 \mathrm{MHz}$ bandwidth, Fig. 2, the raw data rate may reach up to $200 \mathrm{Mbps}$. The broadband (speeds over $1 \mathrm{Mbps}$ ) and the newest arrow band communications use OFDM modulations (Orthogonal Frequency Division Multiplexing) [7] [8].

At present, the more extended standards for Broadband over Power Lines (BPL) in the market have been developed in the frame of two projects: OPERA (Open PLC European Research Alliance) [9] and Home Plug Power-line Alliance [10] [11] [12]. Both projects have finished with some proposed standards which seems to converge to a common agreement based on IEEE standard P1901 [13]. Also in the frame of such projects and beside them, many studies and analysis have been done in order to know better the effect of electrical noise and Electromagnetic Interferences (EMI) on PLC communications [14] [15].

In this paper, several tests are performed to determine the robustness of PLC communications in presence of EMI will be presented. Beside the distortion of the signal, owing to cable losses 
and multipath propagation, one of the main problems for PLC communications are the disturbances in the physical channel. In contrast to other telecommunications channels, PLC does not introduce Additive White Gaussian Noise (AWGN). In LV power lines, the source of noise can be generated inside or outside the power network.

In power lines we may identify five types of noise, usually superposed and independently overlaid to each other [16].

a) Background noise with a relatively low power spectral density (PSD). This can be usually neglected.

b) Narrowband noise. Mostly formed by amplitude modulated sinusoidal signals, caused by the coupling of radio frequency (RF) signals (broadcasting stations, Wi- $\mathrm{Fi}$, etc.)

c) Periodic impulsive noise, asynchronous to the mains frequency, which is mostly caused by switched-mode power supplies (SMPS).

d) Periodic impulsive noise, synchronous to the mains frequency, which is mainly caused by commutation of rectifiers.

e) Asynchronous impulsive noise, which is caused by switching transients in the power network (arcing). The paper is organized as follows, in section II the materials and methods are presented with a description of the different test performed, while in section III, the results of EMI tests are showed. Finally, the conclusions are presented in section IV.

\section{MATERIALS AND METHODS}

Two PLC modems connected each one to a PC (computer B and computer C in Fig. 1) are used to send and receive the data packets. Another PC (computer A in Fig. 1) acts as a

front-end controller of the computers $B$ and $C$ and monitors the whole system. This PC also extracts the Simple Network Management Protocol (SNMP) information from PLC modems and executes the scripts.

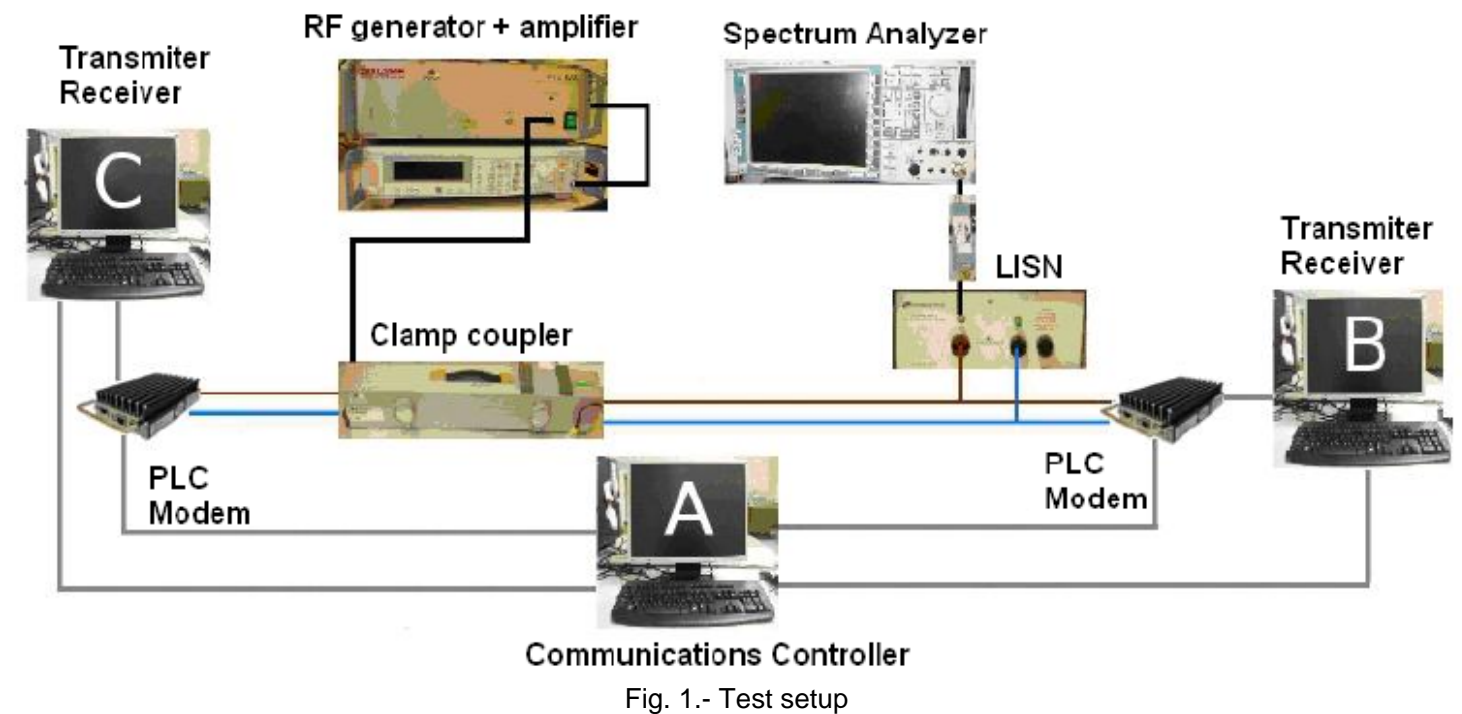

The modems used for the test are model DR200 from DESE, with DS2 chipset [17]. This chipset use the OPERA specifications using a bandwidth of $30 \mathrm{MHz}$ (from $4 \mathrm{MHz}$ to $34 \mathrm{MHz}$ ) as can be seen in Fig. 2. 


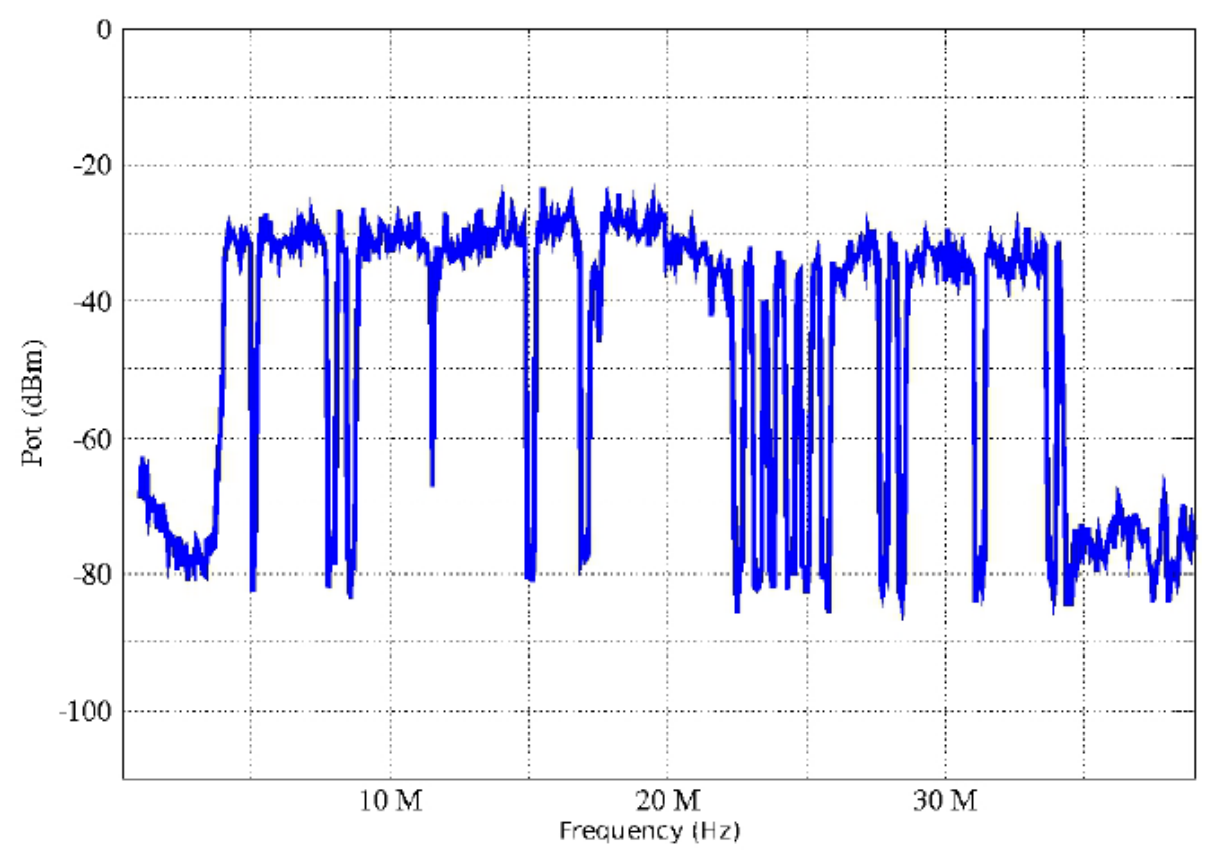

Fig. 2.- Spectral signal of the PLC modems used during a data transmission

Errors on the data communications are used to monitor the EMI susceptibility when the interferences are injected on the power line. The errors are analyzed using the Distributed Internet Generator (D-ITG) [19]. This software has been enhanced by adding some self-made scripts using SNMP protocol [20], to obtain a deeper knowledge of communications parameters, like Signal to Noise Ratio (SNR), bits allocated in each sub-carrier, etc.

To generate the RF test signals, types a) and b), explained in section I, a signal generator, type SMBV100A from Rohde\&Schwarz, connected to a RF amplifier, was used. The amplifier output was connected to an injection clamp, type EM101 from Lüthi Elektronik-Feinmechanik.

The impulsive noise, types c) to e) as described in section I, were generated by a burst generator type CEMaster from KeyTek. EMI were coupled to cables by using a capacitive clamp type CM-CCL from KeyTek.

The power line was monitored by using an EMI receiver, ESPI from Rohde\&Schwarz, connected to a Line Stabilization Network (LISN), type EM-7820 from Electro-Metrics. The measurements were done with a resolution bandwidth (RBW) of $9 \mathrm{kHz}$, with an average detector and a $-6 \mathrm{~dB}$ filter.

The test method allows an easy change of modems and coupling clamps in order to compare the behavior with different test setups.

\section{EXPERIMENTAL RESULTS}

To check the robustness of PLC communications we performed the following tests

1) RF tests, with different test parameters.

2) EFT/Burst test, according to IEC 61000-4-4

3) Tests for capacitive and inductive coupler comparison.

Before the tests were performed, the maximum transmission data rate was found to be 87.9 Mbps. We set this as the reference in order to compare the incidence of each type of noise on the communications. We measured the total error rate (TER), defined as the ratio between non received packets and the number of packets to be sent. In some tests this ratio was split up in two parts: 
a) The ratio between the discarded packets (caused by overflow) and the total packets to be sent.

b) The ratio between the non received packets and sent packets.

\section{A. Interference level for RF Tests.}

For RF tests, the interference signal was placed at $17 \mathrm{MHz}$, with a bandwidth of $26 \mathrm{MHz}$ in order to overlap the maximum number of communication bands. The interference

signal was a sinus wave FM modulated. The power level of the interference signal was selected to be higher than the power level of a normal transmission, which is around $-30 \mathrm{dBm}$, see Fig. 2 . Actually we choose three levels of interference signal: $-30,-25$ and $-20 \mathrm{dBm}$.

With an interference power level of $-20 \mathrm{dBm}$ the total error rate in the communications reached the $37.2 \%$, see Table I, which is too high to obtain any conclusion from the tests. For interference power level below $-25 \mathrm{dBm}$ the TER was similar to that of a normal transmission, therefore we decided to continue the tests with an interference value of $-25 \mathrm{dBm}$ which is slightly above the normal transmission level.

\section{B. RF Tests interfering the whole bandwidth.}

RF tests with interfering signal covering the whole bandwidth have been carried out. Table I shows a summary of transmission error rates at different power levels of interfering signal. The meaning of different parameters in Table I are as follows: SNMP TER is the modem to modem error rate, while the D-ITG TER is the terminal to terminal error rate. The table also shows the average bit rate and the response time of the modems when noise is started and stopped.

TABLE I

COMMUNICATIONS PARAMETERS OBTAINED WITH DIFFERENT INTERFERENCE POWER LEVELS.

\begin{tabular}{|c|c|c|c|c|}
\hline Inteference power level & $\begin{array}{c}\text { Without } \\
\text { noise }\end{array}$ & $\mathbf{- 2 0} \mathrm{dBm}$ & $\mathbf{- 2 5} \mathrm{dBm}$ & $\mathbf{- 3 0} \mathrm{dBm}$ \\
\hline SNMP TER & $0.69 \%$ & $35.69 \%$ & $27.99 \%$ & $27.01 \%$ \\
\hline D-ITG TER & $0.81 \%$ & $37.20 \%$ & $29.79 \%$ & $31.99 \%$ \\
\hline SNMP Average bit rate & $87.9 \mathrm{Mbps}$ & $56.6 \mathrm{Mbps}$ & $63.4 \mathrm{Mbps}$ & $61.0 \mathrm{Mbps}$ \\
\hline D-ITG Average bit rate & $87.3 \mathrm{Mbps}$ & $55.2 \mathrm{Mbps}$ & $61.7 \mathrm{Mbps}$ & $59.7 \mathrm{Mbps}$ \\
\hline $\begin{array}{c}\text { Set up time after noise } \\
\text { addition }\end{array}$ & - & 1 seconds & 1 seconds & 1 seconds \\
\hline $\begin{array}{c}\text { Recovery time after noise } \\
\text { removed }\end{array}$ & - & 15 seconds & 12 seconds & 9 seconds \\
\hline
\end{tabular}

\section{RF Tests partially interfering the bandwidth}

These tests were designed so that the interfering frequencies covered only a part of the communication bandwidth. The transmission bandwidth (4 to $34 \mathrm{MHz}$ ) was divided into three sub-bands, each one of $10 \mathrm{MHz}$, i.e. three tests were performed covering from 4 to $14 \mathrm{MHz}, 14$ to $24 \mathrm{MHz}$ and 24 to $34 \mathrm{MHz}$. Therefore the interference signal was again a sinus wave FM modulated, of $10 \mathrm{MHz}$ bandwidth centered at 9, 19 and $29 \mathrm{MHz}$. 
From Table II, it can be seen that interfering in the 4 to $14 \mathrm{MHz}$ produced a TER value of $12.78 \%$. Interfering the 14 to $24 \mathrm{MHz}$ and the 24 to $34 \mathrm{MHz}$ causes TER values of $24.62 \%$ and $27.69 \%$ respectively. From those measures we can conclude that the data was mainly sent on high frequencies.

TABLE II

COMMUNICATIONS PARAMETERS OBTAINED WITH PARTIALLY BANDWIDTH INTERFERED.

\begin{tabular}{|c|c|c|c|}
\hline Bandwidth & 4-14 MHz & $14-24 \mathrm{MHz}$ & 24-34 MHz \\
\hline SNMP TER & $10.23 \%$ & $21.50 \%$ & $26.59 \%$ \\
\hline D-ITG TER & $12.78 \%$ & $24.62 \%$ & $27.69 \%$ \\
\hline SNMP Average bit rate & $79.0 \mathrm{Mbps}$ & $69.1 \mathrm{Mbps}$ & $64.6 \mathrm{Mbps}$ \\
\hline D-ITG Average bit rate & $76.6 \mathrm{Mbps}$ & 66.2 Mbps & $63.5 \mathrm{Mbps}$ \\
\hline
\end{tabular}

\section{RF Tests partially interfering the bandwidth with carrier sweep across the bandwidth}

To know the effect the modem reaction when a random part of the communication band is interfered, we applied a sinus wave sweeping from $5 \mathrm{MHz}$ to $33 \mathrm{MHz}$ in $1 \mathrm{MHz}$ steps, FM modulated covering a $2 \mathrm{MHz}$ bandwidth. Several tests were performed where the carrier frequency was held for one, five and ten seconds at each frequency, see Fig. 3.

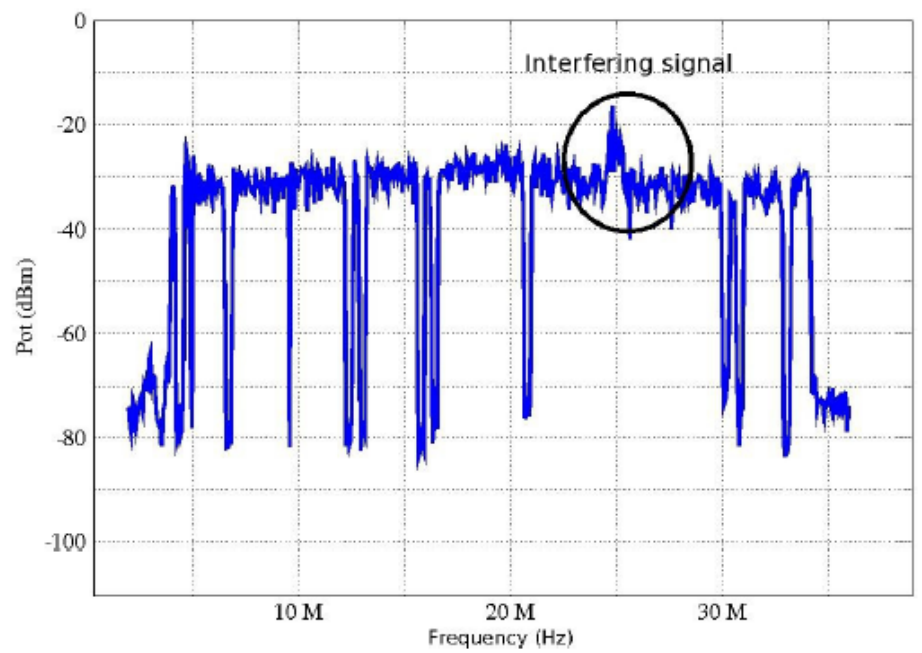

Fig. 3.- Communications signal with the frequency sweep.

From Table III it can be seen that if the interference remains one second at each frequency, the $39.3 \%$ of the packets were not received and the $13.8 \%$ of packets were discarded from the transmission buffer of the modem. When the interference remained for longer time, the $3.0 \%$ of the packets were not received and the $52.8 \%$ of the packets were discarded.

One explanation for that is that when the interference remains during a short time in a frequency slot, the modem can't reduce the speed, neither use the bands not affected by the interference, Fig. 4 and Fig. 5. As the interference remains for longer time in a specific frequency slot, the modem reduces the transmission speed to a minimum and therefore increases the number of packets discarded, Fig. . 


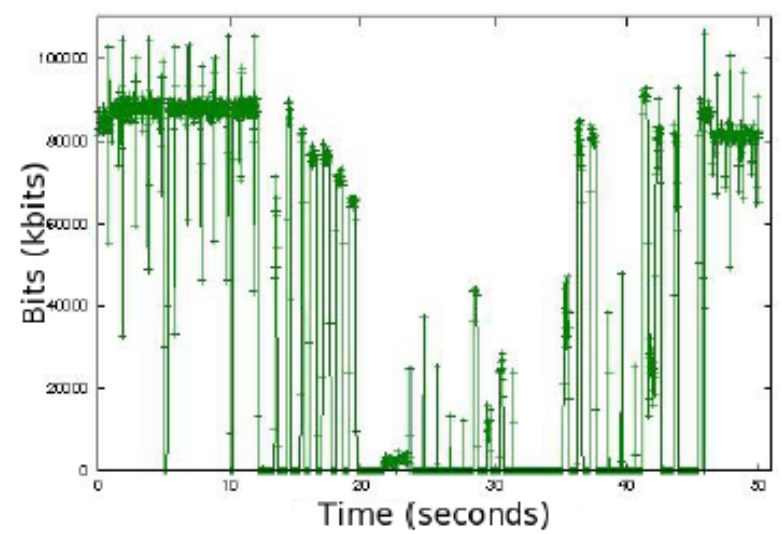

Fig. 4.- Average bit rate in a 1 frequency sweep speed.

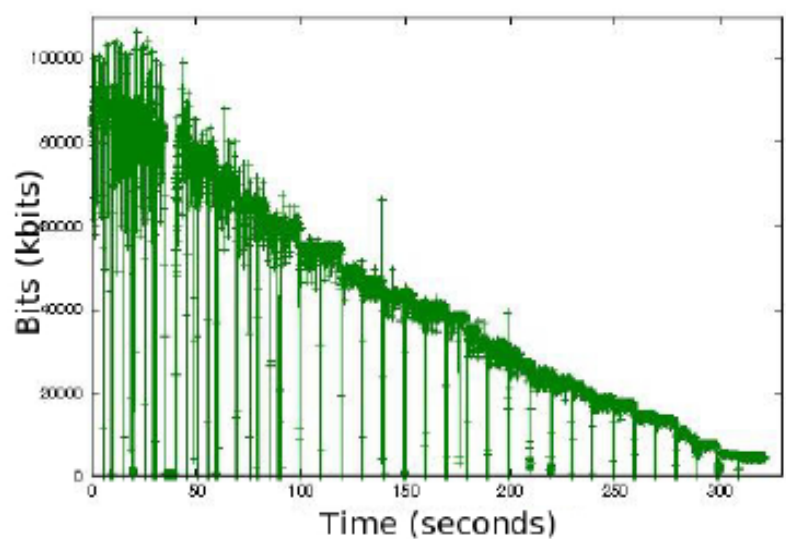

Fig. 5.- Average bit rate in a 10 s frequency sweep speed.
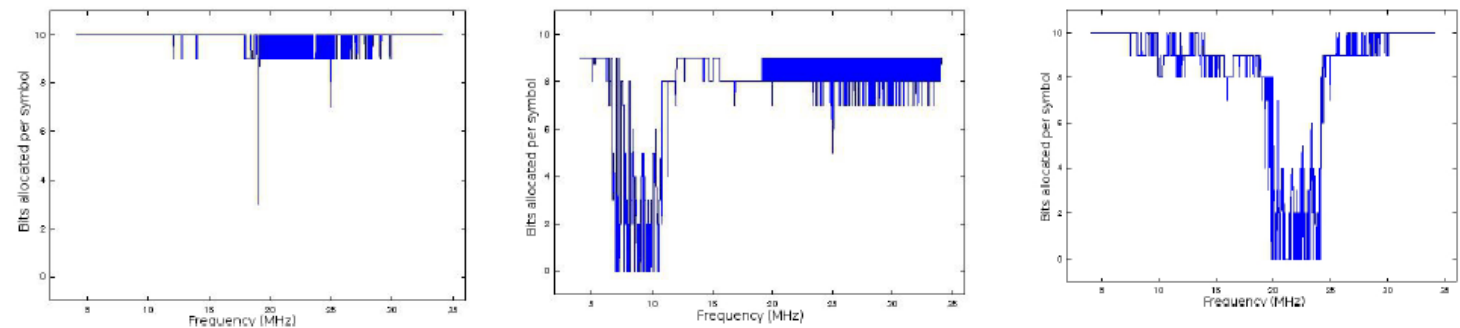

Fig. 6.- Bits per symbol allocated at different instants of a all band frequency sweep, lasting 10 s.

Notice from Fig. 6 , that the modem tries to send more bits in the band with best SNR, increasing the bits per symbol rate (BPS) in the interference free gaps. Table III shows also the average delay of received packets, the discarded packets and not received packets. As the interference remains longer time in a certain frequency slot, the delay and the discarded packets increased and the not received packets decreased. The TER remains approximately constant with the permanence time of interference in each frequency slot. 
TABLE III

COMMUNICATIONS PARAMETERS OBTAINED WITH FREQUENCY SWEEP ACROSS THE BANDWIDTH.

\begin{tabular}{|c|c|c|c|}
\hline Variable Time & One second & Five seconds & Ten seconds \\
\hline SNMP TER & $53.40 \%$ & $54.58 \%$ & $55.92 \%$ \\
\hline D-ITG TER & $58.45 \%$ & $55.78 \%$ & $56.81 \%$ \\
\hline Average delay & $0.040983 \mathrm{~s}$ & $0.158558 \mathrm{~s}$ & $0.184716 \mathrm{~s}$ \\
\hline Discarded packets & $13.79 \%$ & $47.65 \%$ & $52.84 \%$ \\
\hline Channel lost & $39.3 \%$ & $6.89 \%$ & $3.06 \%$ \\
\hline
\end{tabular}

\section{E. EFT/Burst tests}

The impulsive noise coupled to the power line was simulated using the EFT/Burst tests defined in the IEC 61000-4-4. The EFT signal was coupled in common mode (CM) to the power line. The voltage levels used in the test were: $200 \mathrm{~V}, 1 \mathrm{kV}$ and $2 \mathrm{kV}$. Results are presented in Table IV, where all given parameters are the average of five consecutive measurements. From Table IV it's clear that increasing the voltage of the EFT, the TER increases.

TABLE IV

COMMUNICATION PARAMETERS FOR CM EFT TESTS

\begin{tabular}{|c|c|c|c|c|}
\hline Voltage level & No EFT & $\mathbf{2 0 0 \mathrm { V }}$ & $1000 \mathrm{~V}$ & $\mathbf{2 0 0 0 \mathrm { V }}$ \\
\hline SNMP TER & $6.13 \%$ & $24.25 \%$ & $29.85 \%$ & $38.41 \%$ \\
\hline D-ITG TER & $9.52 \%$ & $26.34 \%$ & $31.14 \%$ & $36.23 \%$ \\
\hline SNMP Average bit rate & $82.6 \mathrm{Mbps}$ & $66.5 \mathrm{Mbps}$ & $61.7 \mathrm{Mbps}$ & $54.2 \mathrm{Mbps}$ \\
\hline D-ITG Average bit rate & $79.5 \mathrm{Mbps}$ & $64.7 \mathrm{Mbps}$ & $60.5 \mathrm{Mbps}$ & $55.4 \mathrm{Mbps}$ \\
\hline
\end{tabular}

Table $V$ shows the results of an EFT test comparing the response in common mode (CM) and differential mode (DM). For this test, the signal level was set at $1 \mathrm{kV}$. Notice that, as expected, the resulting communication parameters are very similar, since PLC signal is applied in CM to both live conductors against ground.

TABLE V

CM AND DM PARAMETERS COMPARISON FOR EFT TESTS AT $1 \mathrm{KV}$

\begin{tabular}{|c|c|c|c|}
\hline Cable & 2 cables & Blue cable & Black cable \\
\hline SNMP TER & $29,85 \%$ & $26,65 \%$ & $33,42 \%$ \\
\hline D-ITG TER & $31,14 \%$ & $28,78 \%$ & $34,08 \%$ \\
\hline SNMP Average bit rate & $61,7 \mathrm{Mbps}$ & $64,3 \mathrm{Mbps}$ & $58,4 \mathrm{Mbps}$ \\
\hline D-ITG Average bit rate & $60,5 \mathrm{Mbps}$ & $62,6 \mathrm{Mbps}$ & $58 \mathrm{Mbps}$ \\
\hline
\end{tabular}




\section{F. Couplers comparison tests}

To test the influence of the couplers in the communication parameters, two EFT/Burst tests were performed using a medium voltage (MV) capacitive coupler, see Fig. 4, and a MV inductive coupler, see Fig. 5. The power line used for the tests was a $30 \mathrm{kV}$ cable.

As it can be seen in Table VI, the inductive coupler causes bigger delays and higher TER than the capacitive coupler. More precisely, the TER for inductive coupler reached $24.5 \%$ while the TER for the capacitive coupling was $18.1 \%$.

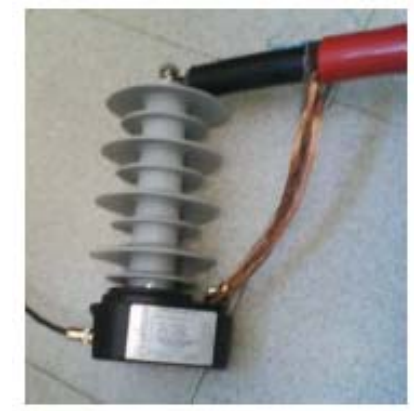

Fig. 4.- Capacitive coupler

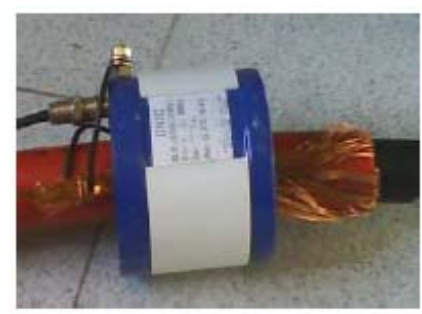

Fig. 5.- Inductive coupler

TABLE VI

COMMUNICATION PARAMETERS OBTAINED WITH COUPLERS

\begin{tabular}{|c|c|c|c|c|}
\hline \multirow{2}{*}{ Test } & \multicolumn{2}{|c|}{ Inductive } & \multicolumn{2}{c|}{ Capacitive } \\
\cline { 2 - 5 } & No EFT & EFT & No EFT & EFT \\
\hline SNMP TER & $6.56 \%$ & $24.21 \%$ & $0.34 \%$ & $18.09 \%$ \\
\hline D-ITG TER & $7.38 \%$ & $24.53 \%$ & $0.92 \%$ & $18.13 \%$ \\
\hline SNMP Average bit rate & $67.3 \mathrm{Mbps}$ & $54.6 \mathrm{Mbps}$ & $71.7 \mathrm{Mbps}$ & $58.9 \mathrm{Mbps}$ \\
\hline D-ITG Average bit rate & $66.6 \mathrm{Mbps}$ & $54.2 \mathrm{Mbps}$ & $71.3 \mathrm{Mbps}$ & $58.8 \mathrm{Mbps}$ \\
\hline delay & $130.95 \mathrm{~ms}$ & $153.40 \mathrm{~ms}$ & $2.72 \mathrm{~ms}$ & $98.83 \mathrm{~ms}$ \\
\hline
\end{tabular}

\section{CONCLUSIONS}

The PLC technology has demonstrated its validity to build communications systems addressed to monitor the electrical distribution system. More precisely PLC is used for remote energy metering, energy management, demand control and safety monitoring. Furthermore, the broadband PLC technology is capable to establish communications over the power grid at data rates of more than $200 \mathrm{Mbps}$. Up to $88 \mathrm{Mbps}$ were measured in our setup tests.

Tests made in this work have shown that EMI susceptibility of the PLC modems, using OFDM, in front of typical electromagnetic interferences, is low. Only in the case that the interferences covered the whole transmission bandwidth, the communications were completely lost. When the communications bandwidth was only partially interfered, the wide band OFDM modems, manage to maintain the communication, either by reducing the transmission speed and/or by reallocating the transmission channel, thus giving a high electromagnetic immunity. 


\section{ACKNOWLEDGMENT}

This research was supported by CDTI (Ministry of Science and Innovation) in the frame of project CRISALIDA, CENIT 2007-2009 in program INGENIO 2010 and by Spanish Ministry of Science and Technology, MCyT, in the frame of project TEC-2007-61582.

\section{REFERENCES}

[1] Srinivasa Prasanna, G.N.; Lakshmi, A.; Sumanth, S.; Simha, V.; Bapat, J.; Koomullil, G.; , "Data communication over the smart grid," Power Line Communications and Its Applications, 2009. ISPLC 2009. IEEE International Symposium on, vol., no., pp.273-279, March 29 2009- April 12009

[2] Biagi, Mauro; Lampe, Lutz; "Location Assisted Routing Techniques for Power Line Communication in Smart Grids," Smart Grid Communications (SmartGridComm), 2010 First IEEE International Conference on , vol., no., pp.274-278, 4-6 Oct. 2010

[3] Sivaneasan, B.; So, P.L.; Gunawan, E.; "Modeling and performance analysis of automatic meter reading systems using power line communications," Communication Systems, 2008. ICCS 2008. $11^{\text {th }}$ IEEE Singapore International Conference on, vol., no., pp.1446-1450, 19-21 Nov. 2008

[4] Lasciandare, A.; Bois, S.; Bisaglia, P.; Moscatelli, A.; , "STarGRID": the first industrial system on chip platform full PRIME compliant," Power Line Communications and Its Applications (ISPLC), 2010 IEEE International Symposium on , vol., no., pp.308-312, 28-31 March 2010

[5] Berganza, I.; Sendin, A.; Arriola, J.; "PRIME: Powerline intelligent metering evolution," SmartGrids for Distribution, 2008. IET-CIRED. CIRED Seminar, vol., no., pp.1-3, 23-24 June 2008

[6] Sanz, A.; Garcia-Nicolas, J.I.; Estopian, P.; Miguel, S.;"PRIME from the definition to a SoC solution," Power Line Communications and Its Applications, 2009. ISPLC 2009. IEEE International Symposium on, vol., no., pp.347-352, March 29 2009-April 12009

[7] Bannister, S.; Beckett, P.; "Enhancing powerline communications in the "Smart Grid" using OFDMA," Power Engineering Conference, 2009. AUPEC 2009. Australasian Universities, vol., no., pp.1-5, 27-30 Sept. 2009

[8] Camplani, M.; Cannas, B.; Carcangiu, S.; Fanni, A.; Montisci, A.; Usai, M.; , "Tabu-search procedure for PAPR reduction in PLC channels," Industrial Electronics (ISIE), 2010 IEEE International Symposium on , vol., no., pp.29792983, 4-7 July 2010

[9] OPERA Project Outputs. Available on http://www.ist-opera.org/

[10] Home Plug Powerline Alliance. http://www.homeplug.org/

[11] Afkhamie, K.H.; Katar, S.; Yonge, L.; Newman, R.; , "An overview of the upcoming HomePlug AV standard," Power Line Communications and Its Applications, 2005 International Symposium on , vol., no., pp. 400- 404, 6-8 April 2005

[12] "HomePug AV White Paper", HomePlug Powerline Alliance, 2005.

[13] IEEE Std 1901-2010, IEEE Standard for Broadband over Power Line Networks: Medium Access Control and Physical Layer Specifications; http://grouper.ieee.org/groups/1901/

[14] Second Report on PLC Standardization efforts in CISPR. The project team CISPR/I/PT-PLT, working on CISPR 22 am3 f1 Ed. 5.0. Available at: www.ist-opera.org/drupal2/files/OP2 D31 v1.1.pdf

[15] CISPR///257/CD Comitee Draft on CISPR 22 am3 f1 Ed. 5.0. Available at: www.compliance-club.com/PLT/ CIS_I_257_CD.pdf

[16] Meng, H.; Guan, Y.L.; Chen, S.; , "Modeling and analysis of noise effects on broadband power-line communications," Power Delivery, IEEE Transactions on , vol.20, no.2, pp. 630- 637, April 2005

[17] "MF-PD-C3-WISC-ALMA V4.0 Features", Design of Systems on Silicon (DS2).

[18] Ndo, G.; Siohan, P.; Hamon, M.-H.; , "Adaptive Noise Mitigation in Impulsive Environment: Application to PowerLine Communications," Power Delivery, IEEE Transactions on , vol.25, no.2, pp.647-656, April 2010

[19] Avallone, S.; Botta, A.; Dianotti, A.; Donato, W.; Pescapé, A.; "D-ITG V. 2.7.0-Beta Manual" University of Napoli Federico II; December 2008.

[20] Stallings W.; "SNMP, SNMPv2, SNMPv3, and RMON 1 and 2 (3r Edition)", Addison Wesley, December 1998. 